\title{
INFLUÊNCIA DO TEOR DE ÁGUA DO SUBSTRATO NO ENRAIZAMENTO DE ESTACAS DE EVÁLVULO BRANCO (Evolvulus pusilus)
}

\author{
Z. PIANA \\ EPAGRI, C.P. 502, CEP: 88034-901 - Florlanopolls,SC. \\ C. CAVARIANI \\ Departamento de Ciencia do Solo - FCAVUNESP, C.P. 237, CEP:16800-970 - Botucatu,SP \\ M.A.A. TILLMANN \\ Departamento de Fhotecnla - FAEM/UFPEL - C.P. 354, CEP: 96010-900-Pelotas, RS \\ K. MINAMI \\ Departamento de Horticultura - ESALQ/USP, C.P. 9, CEP: 13418-900 - Piracicaba,SP.
}

\begin{abstract}
RESUMO: Objetivando verificar a influtacia do teor de agua do substrato no enraizamento de estacas de eválvulo branco (Evolvulus pusllus), conduxiu-se um ensaio sob condiçoes de laboratorio. Os efeitos de cinco níveis de agua no substrato (solo $x$ areia $3: 1$ de $20,40,60,80$ e 100\% da capacidade de retença) no enraizanento, foram avaliados através da porcentagem de estacas enraizadas. Para cada repeticão, 20 estacas apicais, com comprimento médio de $15 \mathrm{~cm}$, foram introduridas a uma profundidade de $6 \mathrm{~cm}$, perfazendo 80 estacas por tratamento. Os resultados permitiram conchuir que o teor de água do substrato entre $50 \%$ e $70 \%$ da capacidade de retençåo, possibilitou enraizamento superior para estacas de evilvulo branco.
\end{abstract}

Descriteres: água, enraizamento, eválvulo branco, Evolvulus pusilus

\section{INFLUENCE OP WATER LEVELS OF THE SUBSTRATE ON THE ROOTING OF WHITE IVY (Evolvulus pusilus) CUTTINGS}

\begin{abstract}
AISTRACT: This investigation was conducted in order to verify the influence of water content of the substrate on the rooting of white ivy (Evolvulus pusilus L.) cuttings. The effect of five water levels of the medium soil $\times$ sand (3:1 $20,40,60,80$ and $100 \%$ retention capacity) on the rooting of white ivy was studied using four replications to verify the percentage of rooted cuttings. Each replication included the rooting of 20 apical cuttings averaging $15 \mathrm{~cm}$, introduced to the $6 \mathrm{~cm}$ depth, totalling 80 cuttings per treatment. The results led to the conclusion that the soil water content that promoted higher rooting was between 50 and $70 \%$ of the substrate retention capacity.

$\mathrm{Keg}_{\mathrm{g}}$ Werls: water, rooting, white ivy, Evolvulus pusilus
\end{abstract}

\section{INTRODUÇÃO}

A água e a substância mais abundante encontrada nas plantas, sendo permanentemente detectável nas relações dinâmicas entre o solo, as plantas e a atmosfera. A sua importancia é permanente durante todo o ciclo da planta, embora possam ser reconhecidos períodos críticos de maior dependência. Nas plantas multiplicadas por semente a fase de estabelecimento em campo, representada pela germinação e pela emergência das plantulas, define um ponto de estreita dependência à disponibilidade hídrica. Do mesmo modo, as especies vegetais multiplicadas vegetativamente necessitam de um suprimento adequado de água por ocasião da sua propagação (BROWSE, 1979; LUCCHESI, 1993).
A propagação por meio de estacas caulinares é um dos métodos de multiplicação de plantas mais empregados para muitas espécies. A preferência por este método reside na facilidade e na rapidez da sua execução. Vários fatores influenciam a capacidade de enraizamento, destacando-se entre eles os componentes bioquímicos da propria planta, bem como as condiģões ambientais que envolvem e afetam o processo rizogênico. Dentre elas encontram-se o substrato, a temperatura e a água (HARTMANN \& KESTER, 1975; BROWSE, 1979).

A água é um fator muito importante para a propagaçäo vegetativa, uma vez que a sua deficiência ou excesso podem conduzir ao insucesso do enraizamento e, até mesmo, ao dessecamento e morte das estacas (CHALFUN, 1989). 
A respiração aeróbica nas raízes das plantas compreende um processo contínuo de absorção de oxigênio e eliminação de gás carbônico. Se a troca de $\mathrm{O}_{2}$ e $\mathrm{CO}_{2}$ se interrompe, há deterioração imediata dos processos metabólicos das raízes das plantas que estiveram crescendo normalmente em solos bem drenados. Um intercâmbio gasoso inadequado pode provocar a morte das raízes (BLACK, 1975).

A busca de novas informações $e$ conhecimentos sobre os fatores que condicionam o enraizamento é muito importante para se obter maiores êxitos na propagação vegetativa.

A maioria dos trabalhos citam a umidade como um fator importante, porém não fazem menção ao teor adequado de água do substrato para o enraizamento (HARTMANN \& KESTER, 1975; BROWSE, 1979). No entanto, COCK et al. (1982), recomendam o umedecimento do solo até a sua capacidade de campo. Em relação a umidade do ar, SILVA (1989) cita valores ao redor de $70 \%$, no interior de câmaras de diferenciação. Em câmaras de nebulização, a umidade relativa do ar normalmente é mais elevada.

Para estudar a influência do teor de água do substrato no enraizamento de estacas elegeu-se o Eválvulo Branco (Evolvulus pusilus) que é uma planta omamental de hábito vegetativo prostrado, de reprodução vegetativa, através de estacas herbáceas, cultivado em jardins com a finalidade de cobrir o solo, formando uma espécie de "tapete". Apresenta flores brancas, pequenas e delicadas.

O Eválvulo foi escolhido para este estudo também por apresentar boa capacidade de enraizamento e pela uniformidade do material experimental (estacas apicais), disponível na horta do Departamento de Horticultura da ESALQ/USP em Piracicaba,SP.

O presente trabalho teve como objetivo verificar a influência do teor de água do substrato no enraizamento de estacas de eválvulo branco.

\section{MATERIAL E METODOS}

O ensaio foi conduzido sob condições ambientais do Laboratório de Análise de Sementes da Escola Superior de Agricultura "Luiz de Queiroz"/USP - Piracicaba - SP, no período de março a maio de 1992.

O experimento constou de cinco tratamentos, correspondentes aos teores de água no substrato solo $x$ areia $(3: 1)$ de $20,40,60,80$ e $100 \%$ da capacidade de retenção do substrato, determinados conforme metodologia descrita por FRETZ et al. (1979), com quatro repetições.

Estacas apicais de Eválvulo Branco com cerca de $15 \mathrm{~cm}$ de comprimento foram utilizadas, removendo-se as folhas basais. Para cada uma das quatro repetições, 20 estacas foram postas para enraizar a uma profundidade de $6 \mathrm{~cm}$, em caixas de polietileno de $39 \times 27,5 \times 9,5 \mathrm{~cm}$. A umidade do substrato foi mantida nos níveis citados através da pesagem e reposição diária da água quando necessário. $O$ controle da umidade foi feito em intervalos de 12 horas, Jurante o período experimental, através de pesagens do substrato.

\section{RESULTADOS E DISCUSSÃo}

Para o enraizamento de estacas de Eválvulo Branco observou-se maior porcentagem de estacas enraizadas no teor de água do substrato de 50 a $70 \%$, o que pode ser visto através da regressão da percentagem de estacas enraizadas $(y)$ em função dos níveis de água no substrato $(\mathrm{x})$ :

$$
y=32,5+2,4054 x-0,0210 x^{2}
$$

Esses dados são concordantes com os obtidos para a germinação e emergência de sementes (RAZERA, 1982 e PIANA et al., 1993). No entanto, diferem da recomendação de COCK et al. (1982), que indicam o umedecimento do solo até a capacidade de campo para o enraizamento de estacas. As sementes são estruturas vegetais modeladas pela natureza para a propagação e apresentam um balanceamento adequado de hormônios; já as estacas, são estruturas retiradas dos vegetais e necessitam redistribuir os hormônios para que o enraizamento ocorra. Normalmente, na base da estaca vegetativa forma-se o calo e posteriormente tem início o crescimento de raízes (COCK et al., 1982). O período decorrido do plantio da estaca até o enraizamento é variável em função da espécie vegetal, época do ano $e$ condições ambientais. Para o Eválvulo Branco um período de $\mathbf{3 0}$ dias é suficiente para se ter estacas bem enraizadas.

Anatomicamente os passos de formação de raízes em estacas, são os seguintes: 1) diferenciação dos tecidos em células meristemáticas - formação do chamado "calo"; 2) diferenciação das células meristemáticas em primórdios radiculares e -3) desenvolvimento dos primórdios radiculares e emergência para o exterior $e$, conexão dos primórdios com as estacas. 
A presença de certas substâncias químicas naturais, denominadas de hormônios, presentes nas partes vegetativas, favorece 0 enraizamento. As auxinas são substâncias químicas relacionadas com o ácido indolil-acético (AIA), de ocorrência natural nos vegetais, principalmente em órgãos que estão em crescimento ativo (regiões meristemáticas, folhas jovens, coleoptilos e sementes) e, causam o crescimento por alongamento celular (VALIO, 1979).

As auxinas podem induzir a dominância apical $e$ estimular a formação de raízes adventícias em estacas (BANDEL, 1979; ZAERR \& MAPES, 1982).

Vários reguladores vegetais que são hormônios sintetizados artificialmente como o ANA (ácido naftaleno-acético) e o IBA (ácido indolbutírico) promovem o enraizamento (CASTRO, 1986; LUCCHESI, 1993), e são muito usados em países como a Inglaterra (BROWSE, 1979). No entanto, devido ao seu alto preço, são utilizados $\mathrm{em}$ pequena escala pelos produtores de mudas no Brasil. Para este estudo optou-se por não utilizar nenhum hormônio artificial, visando especialmente a resposta da estaca em condições naturais. Considerando também que o AIA é sintetizado em abundância pelos ápices dos caules e folhas novas e em pequena quantidade pelas folhas velhas, sendo transportado através dos órgãos sempre no sentido ápice-base (BANDEL, 1979), a disponibilidade de água em níveis adequados possibilitaria uma melhor interrelação entre a água $e$ os componentes bioquímicos da estaca.

Teores de água no substrato superior ou inferior a $60 \%$ da capacidade de retenção reduziram acentuadamente o enraizamento de estacas de Eválvulo Branco (Figura 1). Segundo CHALFUN (1989), tanto o déficit como o excesso hídrico podem conduzir ao insucesso do enraizamento, portanto, existe uma concordância deste trabalho com o do citado autor em termos do fenômeno biológico. Por outro lado, um intercâmbio gasoso inadequado pode provocar a morte das raízes (BLACK, 1975).

$\mathrm{Na}$ propagação vegetativa, em câmaras de nebulização, invarialvelmente não é feito o controle da umidade do substrato. TILLMANN et al. (1994), estudando o efeito de sete substratos diferentes no enraizamento de estacas apicais de cróton (Codiaeum variegatum) concluiram que o substrato vermiculita média mostrou-se o mais indicado. Observando-se as propriedades físicas deste substrato constata-se que ele apresenta um bom espaço poroso total, uma boa retenção de água e um ótimo espaço de ar na capacidade de retenção, fatores que the possibilitam a manutenção de um adequado suprimento de água para o enraizamento de estacas.

A partir dos dados deste ensaio reforça-se a recomendação para que nas câmaras de nebulização os recipientes com os substratos tenham um sistema adequado de drenagem para evitar o excesso de água; assim como, na produção de mudas em sistemas convencionais é interessante observar o aspecto da umidade do substrato para se ter êxito na produção de mudas (BROWSE, 1979).

\section{CONCLUSÕES}

Os resultados do presente trabalho permitem concluir que o teor de água do substrato entre 50 e $70 \%$ da capacidade de retenção possibilita enraizamento superior para estacas de eválvulo branco.

\section{REFERÊNCIAS BIBLIOGRÁFICAS}

BANDEL, G. Desenvolvimento e diferenciação em plantas. Piracicaba: ESALQ, Departamento de Genética, 1979. 159p. (Publicação Didática).

BLACK, C.A. Água. In: BLACK, C.A. Relaciones suelo-planta. Buenos Aires: Edit. Hemisfério Sur, 1975. cap.2, p.75-163.

BROWSE, P.M. A propagaçăo das plantas. Lisboa: Europa-América, 1979.229p.

CASTRO, P.R.C. Fitoreguladores. In: REUNIĀo TÉCNICA DE Fisiologistas do Sistema CoOperativo de Pesquisa Agropecuária, 1., Cruz das Almas, 1986. Anais... Cruz das Almas: EMBRAPA, CNPMF, 1986. p.1-11.

CHALFUN, N.N.J. Fatores bioquímicos e fisiológicos no enraizamento de estacas de Hibiscus rosa-sinensis L. Viçosa, 1989. 85p. Tese (Doutorado) Universidade Federal de Viçosa.

COCK, J.H.; TORO, J.C.; ROCA, W.M. Multiplicacion acelerada de material genético promisorio de yuca. Cali, 1982. 28p. (CIAT. Série 04SC-06-06).

FRETZ, T.A.; READ, P.E.; PEELE, M.C. Plant propagation. Minneapolis: Burgess Publ., 1979. $317 p$.

HARTMANN, H.T.; KESTER, D.E. Plant propagation: principles and practices. 3.Ed. Englewood Cliffs: Prentice-Hall, 1975. 662p. 
LUCCHESI, A.A. Propagação de plantas através da alporquia. Piracicaba: PCLQ/USP, 1993. 8p. (ESALQ/CENA. Informativo Técnico, 13).

PIANA, Z.; CAVARIANI, C.; TILLMANN, M.A.A.; MINAMI, K. Disponibilidade hídrica e germinação de sementes de cebola. In: CONGRESSO BRASILEIRO DE SEMENTES, 8., Fóz do Iguaçu, 1993. Informativo ABRATES, Brasilia-DF, v.3, n.3, p.71, 1993.

RAZERA, L.F. Emergence of soybean (Glycine max (L.) Merr.) seed at various levels of soil temperature and moisture. Mississipi, 1982. 83p. Thesis (Ph.D) Mississipi State University.

SILVA, W.R. Morfogênese "in vitro" de diferentes tipos de explantes em progênies de Pinus caribaea Morelet var hondurensis Barr. et Golfari. Piracicaba, 1989. 138p. Dissertação (Mestrado) - Escola Superior de Agricultura "Luiz de Queiroz", Universidade de São Paulo.
TILLMANN, M.A.A.; CAVARIANI, C.; PIANA, Z.; MINAMI, $K$. Comparação entre diversos substratos no enraizamento de estacas de cróton (Codiaeum variegatum). Scientia Agricola, Piracicaba, v.51, n.1, p.17-20, jan./abr. 1994.

VALIO, I.F.M. Auxinas. In: FERRI, M.G. Fisiologia vegetal, 2. São Paulo: EDUSP, 1979. p.39-72.

ZAERR, J.B.; MAPES, M.O. Action of growth. regulators. In: BONGA, J.M.; DURZAN, D.J. (Ed.) Tissue culture in forestry. The Hague, Martinus Nijhoff, 1982. p.231-55.

Recebido para publicação em 20.01.94

Aceito para publicação em 14.07.94 